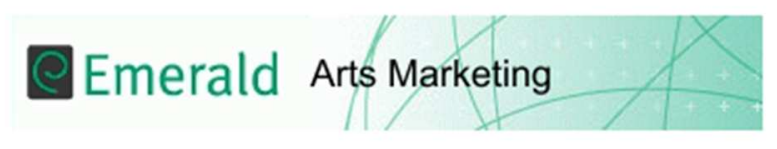

An evaluation of performance arts in generating business value

\begin{tabular}{|r|l|}
\hline Journal: & Arts and the Market \\
\hline Manuscript ID & AAM-04-2016-0003.R1 \\
\hline Manuscript Type: & Research Paper \\
\hline Keywords: & performance arts, devising, change management, improvisation \\
\hline \multicolumn{2}{|c}{} \\
\hline
\end{tabular}

SCHOLARONE $^{\mathrm{M}}$
Manuscripts 
Submitted to Arts \& The Market

Key words: performance arts, devising, improvisation, change management

\title{
Title: An evaluation of performance arts in generating business value
}

\begin{abstract}
Purpose (mandatory)

This paper presents the findings from research that explores the business value of a performance arts-based initiative in supporting change management through devising. Devising is a process that encompasses improvisation to generate social interaction within a community of practice.

Design/methodology/approach (mandatory)

A novel approach is reported on: a case study that includes interviews with key members of partner organizations, representing a business, a performance producer and a commissioning agency, participant observation of a member of the performance production film, and the devising process.

Findings (mandatory)

Findings presented highlight phases of the devising process and the engagement with the creative practices employed. Findings highlight that benefits emerge through the reflexive nature of activities during the processes of creating the performance, as well as reflection on the final performance piece.

\section{Research limitations/implications (if applicable)}

Case study research is necessarily a qualitative design that is not generalizable to a broader population. Findings do, however, highlight potentially useful practices that may be further developed for future research.

Practical implications (if applicable)

Performance arts has pushed previously untested boundaries in employee engagement within the business, resulting in deep understanding between managers and employees on how value may be co-created and redeployed across the business.

Social implications (if applicable)

Originality/value (mandatory)

The paper extends the application of improvisation by situating it within the creative practice of devising. This enables performance to be critically examined as an arts based initiative within business contexts.
\end{abstract}




\section{Introduction}

This paper reports on a case study that examines the role of a devised performance arts based initiative in generating firm value through a process of change management. Much of the literature on the impacts of arts based initiatives highlights that creative practices impact on ideation processes leading to innovations and improved business performance (eg., Schiuma, 2009; Sinfield et al, 2014). Increasingly, organizations engage with artists and artefacts to stimulate new thinking, refocus attention and catalyze change by building new types of knowledgebased assets. As Schiuma (2011) argues, however, the interruptive approach to arts based initiatives, where content and/or artists are helicoptered in to a firm and viewed passively (Fiske, 1999), needs to go further in order to embed competences and skillsets within firm employees so that creativity becomes a sustainable asset, enabling reflexivity in organizations. From the employees' perspective, such engagement with arts has long been understood to have intrinsic and pro-social benefits, from alleviating stress to supporting development of cognitive capacities across teams (Fiske, 1999; McCarthy et al, 2004; Staricoff, 2004; Darso, 2004). Much of the research on which these conclusions are drawn, however, tends to be based on visual and textual arts, with little attention given to contemporary devised site-specific performance. Thus, we explore this artistic medium as an embedded creative practice within a firm, focusing on the roles of aesthetic and emotion in building connections between the firm and its employees through performance as they navigate a period of significant change within their workplace environment.

In this paper, we will firstly review the management literature associated with change, creativity and improvisation before presenting a discussion of the process of improvisation and devising in performance arts practice. Thereafter, we present a discussion of our novel methodological approach, employing three qualitative techniques of interviews, participant observation and devising, within a case context. We present our findings in relation to aesthetic and emotive outcomes before discussing these in relation to the literature.

\section{Literature Review}

\section{Change management, creativity, improvisation and devising}

Change and its effective management are emphasized in the contemporary business context, with the impact of internet enabled technologies, resulting in emergent consumer behavior and adaptations in supply chains that are influencing business practices and consumer culture (Schreyogg \& Sydow, 2010). Increasingly, creativity is highlighted as important characteristic of employees, indeed, creativity has long been associated with strategic approaches to organizational development and change management, albeit most authors highlight this as an ideal skillset of, and process instigated by, key individuals (eg., Weick, 1987; Csikzsentmihalyi, 1988; Sternberg, 1988; Rickards \& Moger, 1999; Prichard 2002; Cochrane et al 2008; Anderson et al, 2014). Only recently has creativity been considered a dynamic and adaptive process involving collective action that may add value to the firm (eg., Bilton \& Cummings, 2010; Cummings et al, 2015). Importantly, Cummings et al (2015) highlight that it is the dynamic group processes of thinking and doing creativity that enable connections between outcomes and original ideas to emerge and become embedded in organizational processes, turning "thoughts into action, doing and active iteration, trying and failing, and learning and recalibrating..." (p. 22). 
The dynamism of creativity as a change agent is particularly emphasized in the literature on improvisation as a tool and technique for organizational management (Kao, 1996; Cunha et al, 1999; Hadida et al, 2015), change (Barrett \& Hatch, 2003; Mantere et al, 2007) and renewal (Crossan et al 1996; Brown \& Eisenhardt, 1997). Described as a means of liberating practice, the literature highlights that improvisation reflects processes that are inherently 'uncontained'. Whilst there has, however, been limited empirical research into the breadth of different types of improvisation that provide support for its theoretical development and future practical application, the analogy of the jazz band is typically used as a metaphor. This is where the shared understanding of a musical genre and its underlying rules of rhythm, enable band members to perform and embellish ad lib (Orlikowski \& Hofman, 1997). The analogies of performance through theatrical improvisation have, however, received considerably less attention than the musical genre of jazz in the literature (see eg., Ratten \& Hodge, 2016).

Within business, improvisation as a metaphor is linked to change management processes that enable employees to take on the roles of performers enacting unplanned responses to unanticipated situations - in so doing, the value generated is 'agile' or reflexive to environmental conditions, enabling organizations to move forwards rapidly albeit within a predefined framework relating to its structure, leadership styles, etc. (Jamebekar et al., 2007). Far from destabilizing the business, as Cunha and Cunha (2010) argue, such an approach is empowering at both strategic and operational levels in building meaning that links historical with emergent practices. Typically, improvisation as an organizational tool for managing change is therefore argued as being most applicable in contexts that present many opportunities, characterized by high velocity and unpredictability and a breadth of experiences to draw upon (eg., Bingham \& Eisenhardt, 2011). It works best, according to Hadida et al (2015), when links between actions are traced to previous activities, in effect "tapping into instinctual ideas that improvisers already know subconsciously." (p. 445). Improvisation creates a visible trace of organizational knowledge through the embodied actions and expressions of employees (Giddens, 1986; Goffman, 1959), be that for change bounded within current practices, or to create structurally new outcomes (eg., Hadida et al, 2015). Thus, within the management literature, analyses of its application have tended to focus on interrelationships between individuals and the organization, leadership styles (eg., Gagnon et al, 2012), tolerance to failure and creative practice (eg., Plowman et al, 2007), primarily from a theoretical perspective. Within the arts, improvisation has a long history as a creative practice having been applied to most forms of Western arts practice particularly during the late $20^{\text {th }}$ and early $21^{\text {st }}$ centuries. It is the practice of open form creativity conducted either in private or public, often involving an audience who 'view an instance of one of many possible realizations of the idea' (Carter, 2000, p. 181). It may be used as a preliminary developmental phase, a form of previsioning (Sterritt, 2000), in the generation of a new final performance, where the audience engages only with the end production. Taking Foucault's (1972) lead that formation is the structural feature of the process of creation, improvisation is viewed as being an important means to challenge conventional and historical practices to introduce new developments in the arts (Carter, 2000). In dance, the means by which improvisation takes place is through the human body, as it interacts with the environment or others engaged in the performance space. Albeit that when experienced in a traditional environment such as a theatre, some have argued it has alienated viewers because it appears to be inwardly focused (eg., Herridge, 1969), others have used the creative processes of 
improvisation as a means to liberate performance from these environments, leading to new possibilities of site-specific works (Carter, 2000; Banes, 1980). Frost and Yarrow (1990) identify three main strands: "the application of improvisation to the purposes of traditional play; the use of pure improvisation in the creation of an 'alternative' kind of theatrical experience; and the extension of improvisatory principles beyond the theatre itself" (1990, p. 15).

The performance and its associated meaning is created through a process of devising, of which improvisation is a key part. Devising emerged as a core creative methodology within community arts practice in 1960s (Heddon and Milling, 2006). For community-based theatre practitioners, it is a process that encourages social interaction, as Govan et al (2009) state: "[devising] encourages individual participants to reflect on their experiences by finding connection with others, in order to construct new social identities and revitalized communities" (2009, p. 76).

Improvisation is therefore the way that original material is generated (Heddon and Milling, 2006) and inseparable from devising (Johnson, 2005). Whilst acknowledging the wide range of devising practices, the authors identify that performance companies will develop an approach that includes consideration of factors such as "the level of involvement of theatre professionals; the level of participation of community members; the relative importance of process or product; and the political impetus of the work..." (2005, p. 136). Devised performance within communities shares the ethos of change of applied theatre practice. In Applying Performance, Shaughnessy (2012) outlines the dramaturgical processes of devising as "research, generating material, improvisation, scripting, editing and rehearsing" (2012, p. 86).

In the understanding and experience of improvisation, performance companies have much to offer other sectors in terms of applied practice. For example, in Culture of Spontaneity (1998), Belgrad argues that improvisation is "indicative of a political moment of resistence to bureaucratization and established institutions" (in Heddon and Milling, p. 8), whilst Joyce Piven (founder of the Piven Theatre Workshop) called to the political world, "we've discovered so much - why don't they come and talk to us?" (Johnston, 2005, p. 6). Drawing on Giddens (1986), the approach also has potential as a management tool: by building upon the nature of improvisation in order to embed knowledge through the structures of the organization, artistic performance may be used as a means to create expression and co-create meaning that transfers knowledge. We next examine the nature of performance and applied theatre, considering how these creative processes build shared meaning.

\section{Building meaning through performance and applied theatre}

There is a sense of simultaneity and co-expressiveness of speech and gesture that is unique within performance arts. In The Call to Performance, Denzin (2003) asserts that performance offers agency and embodiment for participants:

"Performance is an act of intervention, a method of resistance, a form of criticism, a way of revealing agency... Performance becomes public pedagogy when it uses the aesthetic, the performative, to foreground the intersection of politics, institutional sites, and embodied experience... In this way performance is a form of agency, a way of bringing culture and the personal into play" (2003, p.9). 
In Community Performance Reader, Kershaw (1999) describes a performance as an 'ideological transaction' between the performers and audience, in which the spectator is engaged in the active construction of the meaning of the performance: "Ideology is the source of the collective ability of performers and audience to make sense of the signs used in performance, by which aims and intentions of the company connect with responses and interpretations of their audiences" $(1999$, p. 78). Yet there are widely different variations in meaning due to different ideologies of audience members, as Esslin (1987) states, any attempt to predict the 'meaning' of the performance "is bound to be doomed to failure, simply because that meaning must be different for each individual member of the audience" (1987, p. 91). Kershaw, however, recognizes the possibility of a collective response based on shared readings. Shaughnessy (2012) reflects how in applied theatre practice, those taking part in performance develop "an embodied engagement with histories they had not witnessed, which they transformed into new histories/performance" (2012 p. 218). Applied theatre practice therefore aims to create change, making something new by finding "new ways of engaging audiences as participants, developing... interventionalist strategies to challenge or transform existing systems of representation, hierarchies and ideologies" (Shaughnessy, 2012, p. xvi). In applied performance, distinctions between creator, performer and perceiver are blurred as performers and participants engage in creative dialogue through action and interaction 2012 p. 11).

Shaughnessy (2012) has developed a taxonomy of applied performance practice through which to define and evaluate work, structured around seven key themes: pedagogy (engaging in the process of knowledge and identity production), process (the process of making the work is as important as the final piece), play (play-based practices to encourage social engagement), presence (engaging participants in a lived experience in the here and now), participation (spectators actively engaging with work produced through participation and interaction), performance (a dissemination or sharing) and pleasure (capacity to trigger liminal and embodied experiences). As Shaughnessy (2012) states: "A performance authorizes itself not through the citation of scholarly texts, but through its ability to evoke and invoke shared emotional and experience and understanding between performer and audience" (Shaughnessy, 2012, p. 26). Community performance is built on the premise that "artistic practices can have an affect on the social world" (Kuppers and Robertson, 2007, p. 2). Rather than being separate from society with specialist status, artists "become companions in a collaborative search for an expressive relation to the world" (2007, p. 2).

Boundaries between artist, audience and artefact become blurred with a "blending of creative process into the concerns of a community" (2007, p. 2). Kershaw (1999)

differentiates between communities of interest and community of location: a community of interest is characterized by a commitment to a unifying interest; communities of location are formed by face-to-face interaction within in geographical area. In a community of location, any ideological values are implied by the organization (Kershaw in Kuppers and Robertson, 2007, p. 88). An awareness and understanding of this ideology, he asserts, is crucial for a successful performance.

Thus, in applied theatre practice, the process is at least as important as the finished artistic product, McConachie (2008) reflects how both are needed to attain "the dynamics of blending that involve attention, memory, empathy and heightened emotions" (2008, p.19). The involvement of a community in both the creative process 
(the making) and product (the sharing of performance) can have a transitional impact:

“...participation engages audiences differently and cognitively through embodied encounters that can also become performance, as audiences become collaborators the publics become the art, while the continuous present, the physicality of 'being in the room' and in the moment of performance as an event if fundamental to the pleasures generated through both share and individual experiences all of which can be profoundly affecting"

(McConachie, 2008, p.254).

The goal of bringing about change is key to applied theatre practice and the narration of community histories is central to aiding this change:

"Telling stories in drama provides participants with the opportunity to question now narratives of community are performed and embodied, and how they might be disturbed or re-interpreted... Narrative inhabits a space between how life is usually constructed and perceived, and how it might be reconstructed and re-imagined for the future" (Govan et al., pp. 74-5)

Through participating in such narrative-based performance, participants own stories can be "represented, reframed, rewritten and reinterpreted" (ibid, p. 73). Narratives enable communities to make sense of themselves: "building communities is a creative endeavour and an imaginative process, in which the process of narration provides a sense of social coherence... and a way of representing events which makes them meaningful within a particular community..." (ibid, p. 76). The narrative is not necessarily played out through a linear plot, but may use bricolage, collage or montage, where the different parts are in 'fertile contact' (Steinman 1995, p122) with each other, making something new through combination and juxtaposition: "juxtaposition and simultaneity are more the methods of this lively art of inner and outer reality than are transition and linear development" (1995, p. 122).

Applied theatre practitioners inhabit an unusual position, working simultaneously from both within an institution or community setting and outside that community. Kershaw (1999) and Nicholson (2005) regard this as a creative space open to interventions. Thus, in Broadhurst's (1999) notion of liminal performance, the audience finds meaning in the "free association of themes" (1999, p. 77), whilst the "communication that takes place in the auratic moment is one between the present and the past as embodied in the object, but this past is itself dynamic, and accumulation of present moments, including the present in which the object is now observed" (Indyk, 2000 in Shaughnessy, 2012, p. 232). The performance explores interconnections to develop an empathic and embodied understanding whilst the audience blends their individual personal memories with the collective memory.

Taking these multi-disciplinary streams of literature, this research aims to explore how creativity and change management may be supported through the process of devising a performance arts piece, which in turn creates value for an organization. The next section describes the novel mixed-method research design adopted to achieve our aim.

\section{Methodology}

Adopting a case study as a unit of analysis, we seek to provide rich insight into the focal phenomena of devising as a means to support change in an organization (Geertz, 1973). Case studies enable in-depth and multi-faceted exploration of complex data in 
real life (Yin, 2003; Chetty, 1996; Curran and Blackburn, 2001; Denzin and Lincoln, 2003) thus the approach selected is suited to our research aim, being inherently exploratory in nature and bound around a "milieu of social actors" (Perren and Ram, 2004, p. 84). Within this paradigmatic framework, we have used three data collection strategies in a novel research design. Two methods are traditionally associated with the case method in management literature ie., interviews (eg., Gifford, 1998) and participant observation (Jorgensen, 1989). The third method is embedded within arts practice: devising (for a discussion on practice-based research in arts, see Candy and Edwards, 2011). Devising as a practice is described in the previous section, therefore we will not go into further detail at this juncture, suffice to say that the three methods used have been intertwined within the case context: participant observation being used to reflect upon devising practice, and interviews reflecting upon the roles of stakeholders in the firm and arts organization, their previous activities and future developments.

Through the role of participant observer, one of the researchers generated a social identity (Jorgensen, 1989) that facilitated entry into the focal case, relationships with key informants to be formed and access to materials and artifacts including audiovisual recordings of practices, the environment and company materials. Using personal knowledge and judgment formed over months to make sense of actions and communications within the case, the research has built up a refined approach that provides "both a point of reference for the logic and process of participant observational inquiry and a strategy for gaining access to phenomena that commonly are obscured from the standpoint of a non-participant" (Jorgensen, 1989, p. 9). The complementary method of interviews with key informants was used to gather specific information about pertinent issues identified in the investigation.

Following Sudnow (1978), who became a jazz pianist to observe improvisation, one of the researchers performed an active role in the focal activities. Whilst objectivity is best achieved by 'becoming the phenomenon' of interest (Adler and Adler, 1987), the approach necessitates that the researcher remains flexible to identifying, defining and refining the problems investigated, as well as the data needed and techniques used for its evaluation (Glazer and Strauss, 1967) at an holistic level. Such flexibility requires the researcher to sustain access over time in order to collect accurate and truthful data (Johnson, 1975). Thus, the role taken in this study was overt insofar as the identity of the researcher was concerned (she is and was a member of the performance arts organization) and this has resulted in high levels of trust and cooperation from key informants over an extended period of time. Experiences of the researcher contribute to an 'insider's view' of the case which is supported by the considerable data collected (Jorgensen, 1989).

Adopting a thematic approach to analysis of data collected (McCracken, 1988), the findings informed the devising process and subsequent data collection stages, which iteratively reflected on and informed emergent arts practice. Objectivity was therefore a balance of engaging in sufficient dialogue to build rapport with the stakeholders in the case (Angrosino and Mays de Perez, 2003) through the devising phase, whilst interviews were conducted by third parties following a semi-structured brief. Findings were discussed with key informants during the data collection phases, a process identified by Dewalt and Dewalt (1998) as good observational research practice and technique for improving validity. In this way, the practice-based 
researcher attempted to remain neutral, if not wholly impartial because the very nature of such investigation is intrusive and therefore has potential to alter behavioural patterns. This is acknowledged as being difficult to evaluate because it may only emerge some time after research has completed although interpretations may differ at subsequent stages of the research reflecting new knowledge acquired (Angrosino, 2008).

A summary table of data collected is presented at Table 1 .

insert table 1 about here

\section{Case background}

The case was initially conceived as an arts-based project between three partnering organizations: a strategic arts programme (commissioner), a business (host) and a live art company (producer), one member of whom is the participant observer reported on in this paper. Given the novel nature of the project and knowledge generated through the collaborative research processes, the firms involved are identified and therefore, with permission, we attribute the comments made by respective members of the partner organizations. The host business was Elsoms, an agri-business located in the East of England (UK) that at the time of the project (summer 2014) was undergoing a significant period of change in its operations as old facilities were merged with a new state-of-the-art seed packaging warehouse. Elsoms is the UK's leading independent plant breeding business, specializing in seed priming and treatment. Established in 1844, the firm remains an independent family-owned business. Transported (commissioner ${ }^{1}$ ) had commissioned Assault Events, the producer, to create a performance for and about Elsoms to be premiered at the opening of the new warehouse on site. Assault is a live art company combining contemporary dance and theatre, new writing, music and design to create accessible, innovative performance events. Assault's work challenges preconceptions about what art is and who it is for, specializing in non-traditional theatre spaces and site-specific environments, using the devising process. This incorporates a collaborative approach to producing creative pieces, working with audiences as creative collaborators to reflect the needs and wants of the public. Creative consultation and collaboration takes a variety of forms including discussion groups, creative workshops and online collaboration groups where individuals can upload ideas and material, and interviews.

Assault devised the performance on-site at Elsoms, with empirical processes taking place during a six weeks residency, having been planned for a year prior. A programme of creative activities was developed that culminated in an original piece

\footnotetext{
${ }^{1}$ Transported is a community-focused programme that aims to increase arts engagement in the Boston Borough and South Holland regions of Lincolnshire, UK. Funded by the Creative People and Places fund from Arts Council England (which focuses investment in parts of the country where people's involvement in the arts is significantly below the national average), the investment encourages "longterm collaborations between local communities and arts organisations... and aims to empower them to experiment with radically different approaches and develop inspiring, sustainable arts programmes that will engage audiences in those communities."
} 
of site-specific live performance incorporating dance theatre and live music. This initiative generated opportunities that aimed to interrupt Elsoms employees' daily routine, stimulating creativity and collaboration in the workplace and directly engaging staff in the creative process. The final performance piece was 35 minutes in length, themed around Elsoms' employees, their experiences of the workplace, the relationships that are made within it and the connections between work and personal lives. The project was developed to be community-focused in every aspect - from being based within the workplace community, through drawing on firm community experiences, through accessible creative activities, developing themes and artistic content and sharing work-in-progress, to performances within the workplace community.

Each of the partner organizations involved in the performance had identified objectives. For Assault, the aim was to inspire individuals and communities to take part in live art through a range of accessible and high quality participatory experiences and to inspire a business to recognize the value that creative arts participation can have on their workforce.

\section{Research and devising process}

For the purposes of this paper, we focus our discussion on the aesthetic and emotional aspects of performance that are generally disregarded within the workplace. These aspects have been selected because they reflect the strands of relevant literature on creativity and change management in organizations. Within the case, the focal aspects reported on assisted employees to explore their prior knowledge and historical practices to develop new practices. Specifically, we examine the critical features and longer-term impacts of the devising process, the performance and the kinds of values generated, including organizational dynamics and outcomes.

The research and devising process comprised five distinct phases, each with different objectives -

(i) research and development;

(ii) devising process;

(iii) inspiration, consultation, building and empowering;

(iv) performance, empowering and delivering; and

(v) evaluation.

Each is now discussed.

\section{Phase 1 Research and Development}

This phase was focussed on research and development, and was designed to consult with and inspire workplace employees. Following planning meetings with Elsoms' senior management, the producer and arts practitioners (performers) met and ran consultancy sessions with employees, developing ideas around the theme of the piece through direct input. For Assault, the main outcome of this stage was to reassure the business by developing understanding and building confidence in the project outcomes. The business chairman reflected: "It felt like quite a gamble, going ahead with it. Because it was a contemporary dance proposal - it that is not the most accessible art form for people to get involved... at each stage there's a nervousness about getting involved... I had a concern that this could end up being really embarrassing and I could lose credibility for getting people involved with something that 
was just daft. So that's the fear but then you go, what the hell, let's just do it and see what happens" (firm, chairman).

Employees were at best sceptical about the project, their roles and its impact on the business, one stating: "this isn't what Elsoms do". Other members of the business remarked:

"When we were first emailed about it everyone said 'what the hell'?! We hadn't heard about anything like that before... I think people had got this image that they were going to be asked to prance about in costume... "; “... you can imagine people were saying 'waste of money'... then I think as you went on, a few more people would have liked to be involved but... were a bit worried about what other people would say" (firm, employees).

Following negotiation with managers, the producer and performers were encouraged to spend time in different areas of the factory exploring potential material for the performance. During this period, ideas were developed with employees in different ways, enabling people to become engaged in ways that suited them and that they were comfortable with. Activities included team meetings, individual conversations and a postbox for anonymous comments, thoughts and ideas. For many, this was an unsettling experience:

"Some people here have never been to see a show... They were very worried about what you were going to do and whether they would be dragged in to do stuff... for the first few weeks when you were here, it was like 'ooh no, I'm not going to do that"' but Assault's practical approach assuaged fears, as another states: "when [Assault] got involved, it all fell into place. Lots of guys who were initially pessimists enjoyed it" (firm, employees).

This process of negotiation for involvement, resulted in buy-in from firm employees and was recognized as a critical part of the success of the project. As the firm chairman comments:

"You've got to get over a barrier at every stage. The barrier is the person with whom you first have contact, to get them on side, then you've got to get senior management on side... I think that it really comes down to, at each level, people have got to have an attitude of 'give it a try" (firm, chairman).

Phases 2 The devising process and 3 Inspiration, consultation, building and empowering

Phases 2 and 3 are intertwined. Using the devising process, Assault's approach resulted in creation of an original piece, drawing on and developing material from Elsoms (see Table 2). A member of the Assault team comments:

"We were really open at the beginning. Because it's a devised piece, we were going to come and use ideas of the people who work here and ideas from the site. We came on Monday and we didn't have anything. But that was what we're expecting - it's an exciting way of working" (producer).

The piece was created in the canteen area at Elsoms, allowing employees to have maximum contact with and access to the producer and performers, and the creative process. Employees encountered performers making work every refreshment break. During the initial devising stages, the producer and performers would explore the 
spaces at the business, supported by managers. This enabled employees, the producer and performers to become familiar and comfortable with each other:

"Rather than doing formal interviews, we walked around the factory with people showing us what they did [they] didn't stop talking the whole time. We didn't record it, it was important they felt comfortable, it was just for us to get a sense of what that was and how it all worked' (producer).

The approach to engagement took devising to the level of time and space of the employees, and helped to build bridges between employee and artists. As a firm member states:

“...it was nice for people to speak to someone about it. You were actively going around the site and asking questions, about what their job involved, for them it was good to talk about it with somebody. For an external visitor, taking an interest was good" (employee).

This comment is also reflected by the producer:

"There were different levels of engagement. There were some individuals who were really, really involved... and it wouldn't have worked without them, all the way through to just bits and bobs we'd pick up from being here any being around the site... [some employees] took on roles that would normally have been taken on by professional arts practitioners... People perhaps talk about the restrictive nature of businesses, but actually we've had more resources here than we've ever had in a traditional theatre. How often do you get people say 'oh, we've got a forklift you can use'?!' (producer).

The result was participation beyond providing access to the site and an overview of the various business related activities, with some employees providing voiceovers and others providing costumes. Some also helped with sound recording for the performance.

Assault developed the idea for making a performance piece that celebrated the work of Elsoms' employees, albeit they were reliant on employees for the material to be included in the performance. Understanding the nature of the business was essential to the development of the piece, as a member of the producer explains:

"...people took us on really detailed 2-hour tours of seed treatment, really explaining the processes. To get that that level of understanding meant that you understand the company much more and it makes your job of making a show so much easier because you're reflecting that back rather than just knowing there is seed treatment, we actually understand what those guys do" (producer).

insert table 2 about here

Such a level of understanding could only be reflected through a residential level of involvement in the business, as the commissioning partner states:

"It was absolutely essential that we were here [on site at the firm] ... you start to build a relationship so you can just have a chat with them or you can say hello while you're walking around on site and then you just get more information and you get a feeling for what its like to be here because of the feedback they're giving you. If we'd have come in, learnt about it and then 
gone somewhere else to rehearse it would have been a very different thing. I think that being on site was on massive importance" (Commissioner)

This is also reflected in the recognition by the firm that work teams were engaged with different practices relating to the seasonal pressures of the agri-business. Ultimately, this meant some employee teams were more accessible than others for participation in the initiative.

It was agreed between the producer and the firm managers that the final performance would take place in the new warehouse. The commissioner describes how this ambitious decision presented numerous challenges, with the performance situated amongst seed containers and working machinery. Within minutes of completion, for example, the warehouse would be filled with product, albeit that electricity had not yet been installed putting constraints on the use of professional dance-theatre performance tools such as stage lighting and projection equipment. This meant that flexibility and patience were important qualities that were built into the performance piece, as the producer comments:

“... even though it's a new space it's a working space so we have to be really adaptable. We'll go in one day and they'll have been a load delivered that the following day will be taken away, so it's very much working around what is in there at the time, but that's a good challenge" (producer).

Phase 4 The performance, empowering and delivering

The new piece, entitled 'Elsoms Creates', was premiered on 9 September 2015. Two performances took place, one in the daytime for employees and one after working hours for employees and family members plus an invited audience including school groups. Interviewed before the performance, the producer reflected:

"It is a celebration of this place and the people that work here. Hopefully we've made something that is accessible to them... I'm not saying that everybody will like it... but as long as we get them talking in someway then that's a good thing. I think we've done our very best to make it something that they can relate to and they can be proud of having been a part of it' (producer).

Rather than a direct representation of business practice and narrative of workplace day, the piece explored key themes of nature, technology, people and place. Elsoms felt that this approach worked well. As this employee states:

"I saw the rehearsals in the canteen, but to see it all put together, it just flowed, with lots of different elements, the history, where we are now, it had elements of the seed treatments we do, all interpreted through contemporary dance. There were elements of what we do here... [but] it added a completely different element to it, even the scene that was based around seed treatment, shown through dance" (firm, employee)

For the firm chairman, a member of the original founding family, reflections enabled him to make connections to key events in the history of the business:

"I remember the particular parts of it - the start was very effective, the dancers coming out of boxes from behind polythenes, tearing their way out and using a teleporter in the background... and I remember there were definite switches in themes between dark themes of family bereavement and moving on, kind of a rebirthing theme, and then secondary theme was seeds, 
the very practical side of what they are and what they do, and then people in the company, names being sprinkled into the themes as well... the most memorable bit - that entrance, the starting scene... there was an almost a germination aspect to it, the start of life" (firm, chairman).

The emotive nature of the performance was therefore considered important and useful in connecting employees with the firm's values and its changing environment:

'It made everyone feel that we were doing a pretty good job here, and that was very effective... Just being involved in an arts project is a pretty progressive move in itself. The evolution of the business, I think it referred back to it in its historical theme, in its antiquated times of the business. It talked about our seed technology side of the company, which is quite cutting edge. It talked about colleague involvment which is crucial to us' (firm, chairman).

This sense of connection was also evidenced in employee comments: "...I thought that was really good. It made you come out feeling pretty good about Elsoms.” (firm, employee).

Most importantly, meaning was achieved by reflecting the roles of employees and their work in the performance. One employee spoke about the response of a colleague:

"... she was so thrilled when she saw the priming dance and she said 'they know' and she realised that you'd got it. She was so excited... [Assault must have] watched it in slow motion, because that it exactly what the seed does." (firm, employee).

Phase 5 Evaluation

Evaluation enabled partner organizations to assess the success of the project and to draw out key points of learning. Elsoms' employees were consulted on the feedback process, resulting in design of an evaluation strategy that also fed into the commissioning partner's evaluation strategy, including the producer. Formal evaluation meetings were held between the commissioners and the firm, and the producer and the firm; informal evaluation discussions with employees were facilitated by the producer and commissioners. Performers and the producer fed back through semi-structured interviews.

\section{Further findings}

\section{Reflections on processes and actions}

Elsoms' management felt the artistic model used in this work reflected the firm routines, enabling employees to engage with the creative process at levels they were comfortable with, suggesting its potential for application in other firms. A firm manager commented:

"[the model doesn't] interfere with your everyday work, which is probably a concern for everybody and that they're not all going to be press-ganged and dressed up and told they're going to play a lead character. And I think that's probably a fear in some people... So I think if you make it plain that people can participate as much or as little as they like-it's an evolving process really" (firm, manager). 
The high levels of engagement resulted in some employees becoming part of the creative team, involved in production and the final performance of the piece. Its success for the firm was such that some employees, post event, commented on their frustrations with personal workloads that precluded them from being more actively involved. As one employee stated:

“... that's' the only difficult bit - when you're in the work environment and people are expected to do their jobs they can't just drop everything and come and take part." (firm, employee).

This had the impact of attracting other less engaged employees to the final performance as audience members, thereby ensuring meaning was transferred across the workforce, and at different levels of meaning.

For the producer, the co-creative experience was considered to be positive, particularly in relation to the preliminary activities that engaged employees. As the producer reflects:

"Without a moments hesitation, if you ask for something you get it and that's from every member of staff... Obviously we're not full time members of staff so there are limits to the integration but they have made us so welcome - its been an amazing project and I'm really going to miss Elsoms." (producer).

The importance of social space in the workplace meant that the processes adopted through the residency were central to its success, reflecting the core values of the firm. As noted by the chairman, however, this may not always be possible for firms in other sectors:

"I guess there's a lot of companies which are very fast moving production companies and on really tight margins, and when you're processes are constantly fire fighting, trying to get things out the door ... arts project? No! It's only the sort of thing you can do, I think, in a quite well established company which is quite long-termist... Our colleagues are long-term as well, they're part of our history..." (firm, chairman).

\section{Reflections on the performance}

Reflecting on the final performance the chairman relates to the risk taken by the firm in engaging with performance arts and the project processes:

"It was a great relief to me that it reached a decent amount of people and they enjoyed it... it wasn't a farcical embarrassment, which at the other end of the spectrum it could have been. Worst fears were not realized and lots of positive things came out of it, and it did end on a feel-good, these were Elsoms values, we're a community working together and I think it ended on a very positive note" (firm, chairman).

Engagement with the final performance was high with employees from across the business attending both performances, the second with family members. The overwhelming response was one of surprise, as this employee states:

"We've never experienced anything like this before. We were pleasantly surprised. It was different. I think, we're not used to this in the workplace and we weren't sure what to expect... as you carried on watching you got into it more, got involved in it more" (firm, employee). 
For Elsoms the project succeeded in bringing the workplace community together through a positive participatory experience. For Elsoms, its strengths lay in reflecting and reinforcing key values of the company, principally by connected the firm's history with its current and future context through the workplace, its employees and their developing roles. As the chairman stated:

"... probably thinking about memorable moments, the final act was about what it is like to work for Elsoms, with clips of interviews with people being very positive about its like to work for Elsoms. For me, that was reinforcing values which I think are important about being here and being in a community at the company with some quite long standing employees and form a long standing team. That was more important rather than the functional practicality of it" (firm, chairman).

Extending this, one of the commissioner members commented:

"... there has definitely been a lot about staff morale, and one of the things that they found, that they're trying to progress with is the idea of bringing the different departments together, and ownership over the work that they do. That's been one of the really key things." (commissioner).

And, as another commissioner commented, the project helped firm employees to think about their own lives in more depth:

"It's non-work yet it clearly did relate to work and it made people reflect on their own job, their own company that they work for... It wasn't just a bolt-on, an extra 'fluffy' something, it was actually something that in someway made you think about what you do, which ultimately is what art is for." (commissioner).

Elsoms' employees identified how the opportunity had presented them with new ways to consider their workplace roles and their individual contributions to firm. This was particularly helpful for those who were confused about their future status in the changing environment. The performance was felt to be particularly helpful in repositioning perspectives, as this employee stated:

"When you're working in there everyday you're doing the same things and you don't think that your job has any importance or excitement in it, but you guys coming in has energised me..." (firm, employee).

The personalization of experience through performance was considered a useful process, as the commissioner reflected:

"It's their story and I think that resonated with them. It's about [the employees] from the start to the current day of Elsoms and how it's developed and where they want to go and a bit of reflection and so, because the story of Elsoms was told through the medium of dance, then they will remember it. It's their work story" (commissioner).

Largely, this was achieved through emotional engagement:

"... [staff] got emotional, they didn't realise that the arts could have that emotive effect. Most of them wouldn't have known what contemporary dance was ... everyone's story was relevant." (commissioner).

The project resulted in firm managers gaining new understandings and insight into the scope of business capabilities through employees. The chairman comments: 
“... it made me much more confident in our ability to do new things completely off, outside of our normal scope, and that people would be willing to engage in it. That kind of feel good atmosphere made me realize that people really are quite proud of what we do here. I was really pleased to see that. As a figurehead for the company, to understand that, when we're talking about what we do with great enthusiasm, that it is genuinely engaged with by people, and they're proud to be part of the longstanding company. It definitely improved my understanding of what people think of us internally" (firm, chairman).

Immediate benefits were perceived to be a more positive workplace environment, which in turn was identified as having potential future impacts particularly by building community, memory and understanding of the business and connections between employees. It was, however, seen to contribute more than teambuilding, reflecting the firm values as a whole:

"... for us it was offered to us and its an interesting project, but its about creating a place that's interesting and enjoyable to work in, with more aspects to it than just work... its good to bring in the arts activity as well, because it makes this place a more interesting and enjoyable place to work in. Hopefully that makes people enjoy working here more, and hopefully that has some outward facing impact, maybe that will have some impact on the quality of people we have working here, and the enthusiasm in the way in which they go about their work, that may impact on suppliers and customers. It may do none of the above, perhaps that doesn't matter, as long as it makes it a more enjoyable place to work... As an independent company we're able to do that, just because it feels like the right thing to do, rather than just having to justify on the strict investor-proposal-opportunity basis." (firm, chairman).

For Assault, the performance supported aims to exchange ideas that connect the working lives of the firm employees in an accessible and inclusive performance event:

"Ideally, we will have demystified the arts slightly, specifically dance... You don't need to understand everything that's in it but its not putting up any walls to you trying to understand it, there's nothing that's trying to alienate them... Because of the nature of business you're constantly looking forward so it's quite nice that this piece has had a chance to look back on what has made Elsoms what it is now and hopefully that's what they'll get out of it - that chance to say this is where we've come from, this is where we are now and to celebrate the success of what's going on here and to people that work here." (producer).

For some, the interest of enrichment of the arts was reignited through the exchange processes adopted:

"I got a hell of a lot out of it. It's got me playing the violin again. I honestly haven't played in front of people for 20 years and now I want to again and want to find an orchestra or do something." (firm, employee).

Consequently, the profound outcomes from the project for the firm has encouraged it to explore the values of a performance arts initiative further with a new initiative. The chairman comments: 
"If it's not a major distraction from people's day to day work, which I think could irritate people, it's a great way of looking at the business afresh and bringing something different into the daily routine." (firm, chairman).

The commissioner regards the success of the project as 'absolutely fundamental' in developing the new initiative, and supporting the development of a long-term partnership between the partners. The next arts-based initiative will be a photography project targeting all employees, which has already whetted their appetite:

"... we all need to be a team and work together but we're all busy so that sometimes means I don't get to see what happens in the fields and trials, or seed treatment department. The idea is to bring us all together as a team to see what each department does and learn more about photography at the same time, create an archive of images from past and present, to where we've come to, for everyone to share and talk about... bringing this kind of creative empathy in the company." (firm, employee).

This reflects the perceived importance of keeping the momentum of employee engagement alive, whilst at the same time using historical actions to build future heritage.

\section{Conclusion}

This paper has reported on an empirical case study that presents a novel approach to supporting creativity and change management through a devised performance arts initiative. What is particularly interesting about the reported context is that change within the environment, whilst a function of practice modernisation and new technology, is less about the dynamics of the environment (eg., Hadida et al, 2015) and more about ensuring business continuity through the exploration and passing of existing knowledge on to firm employees. In this way, the processes described demonstrate a deep level of business engagement in co-creation of value that builds community and shared meaning by connecting emotion to the aesthetic. This is consistent with Cummings et al's (2015) view that it is the dynamic group processes of 'creativitying', their term for the creative process, that connects emergent practices with original ideas - and indeed extends well beyond the typical 'interruptive' capacities of arts based initiatives such as those outlined by Schiuma (2009) and Fisk (1999). As shown, reflecting Giddens (1986), this has potential as a management tool: knowledge is embedded through the structures of the business that may be redeployed to support periods of significant change (in the case, the bringing on stream of a new state-of-the-art warehouse). This has not been a passive process but through devising, encompassing improvisation, performance and applied arts dramaturgical practices can develop meaningful and transformative social interactions (Govan et al., 2009). What is evident in the case reported on in particular is the nature of the dynamic processes of devising and improvisation, reflecting both change (eg., Mantere et al, 2007) and renewal (eg., Crossan et al, 1996). In this sense, improvisation is not a metaphor for change (ie., Jamebekar et al, 2007; Orlikowski \& Hofman, 1997), but is the mode of engagement used to creatively generate transferable knowledge through emergent practices of the producer and firm (Giddens, 1986; Goffman, 1959).

The processes used in this case have been useful in breaking down barriers between teams of employees across the firm, and between the firm and the performance artists, generating not so much a linear story but a shared experience and memory about 
place, work and people. Indeed, we consider the processes to have been instrumental in revealing agency and embodiment of the firm (eg., Kershaw, 1999), which has been the core of the success of this project. This reflects Foucault's (1972) ideas that it is the formation process that enables extant practices to be challenged. Devising as an iterative approach, demonstrated in this work, is therefore potentially useful as a means to connect individuals and groups with past, present and future practices ('new understandings') by encouraging playful interactions (Heddon and Milling, 2006; Belgrad, 1998), rather than bureaucratic or autocractic processes typically associated with firms and change management processes.

In analogies of the jazz band or theatrical performance in management literature, little is made of the role of audiences in the creative process. This research has, however, highlighted the importance of audience as participants in the creative dialogue (Shaughnessy, 2012). For example, our research identifies the growing significance of participation among firm employees, and the increased sense of ownership in relation to the outcomes of the final performance, both aesthetically and emotionally, as a consequence of their varying acts of participation. Whist there is evidence in the data of some resistance, we evaluate this overall as a form of 'positive engagement', given the outcomes observed. Kuppers and Robertson (2007), in the performance arts literature, have emphasized the 'companionship' between performers and audience that results in values becoming ideologically shared. Although our research suggests achieving this takes considerable effort and planning to build trust over time and space, such outcomes may become deeply embedded in corporate memory, ultimately having a transitional impact. Whilst the devising process has reimagined and reinterpreted historical facts relating to the firm in the case, what is unclear from our research is the extent of impact on collective memory of the firm resulting from the new combinations of knowledge. Indeed, this aspect of our investigation remains somewhat elusive!

Thus, our contributions to future research are twofold: firstly, having explored how creativity and change management may be related to performance arts creative processes through improvisation, we have identified potential modes of engagement that may inform future development of theory and practice: creativity, emergent practices, embodied knowledge and audience participation related to aesthetic and emotion. Secondly, we have presented a novel research design that incorporates devising, an artistic form of improvisation, with traditional data collection techniques to shed light on how change management may be performed in an organizational context. Whilst there are weaknesses with our research design, such as those typically associated with small sample sizes and the specific methods selected, we have attempted to address these through a multi-method and, indeed, multi-disciplinary approach that enables us to generate rich insight into the focal phenomena.

Notwithstanding this, insight may be further developed by taking a more longitudinal approach to data collection than has been possible in that reported on in this paper. Future research could therefore revisit the case to explore how memories and impacts generated through the performance arts initiative have been retained and reused by the firm in its dynamic development. It would also be useful to extend the phases of the research and devising process developed for this study into new domains to explore its validity in a range of different types of business context. For example, the notion of negative resistance to the devised intervention as a mode of engagement in creative change processes in our research has not been discussed, primarily because it did not 
emerge as a finding in our analyses of data. Yet, it may well be that such resistance exists and becomes a barrier not only to dynamic adaptations at some future juncture.

\section{References}

Adler, P.A. and Adler, P. (2000), Observational techniques, in Denzin, N.K. and Lincoln, Y.S. Handbook of qualitative research, $2^{\text {nd }} \mathrm{ed}$, (pp. 377-392), Sage, CA. Anderson, N. Potocnik, K. and Zhou, J. (2014), "Innovation and creativity in organizations: a state-of-the-science review, prospective commentary and guiding framework", Journal of Management, Vol. 40, No. 5, pp. 1297-1333.

Angrosino, M. (2008), Doing ethnographic and observational research, London: Sage.

Angrosino, V.M. and Mays de Perez, K.A. (2003), Rethinking observation: from method to context, in Denzin, N.K. and Lincoln, Y.S., Methods of collecting and analyzing empirical materials, London: Sage.

Banes, S. (1980), Terpsichore in sneakers: post-modern dance, Houghton Mifflin, Boston, p.7.

Barrett, F.J. and Hatch, M.J. (2003), "Planning on spontaneity: lessons from jazz for a democratic theory of change", Organizational Development and Change, D1-D6. Belgrad, D. (1998), The Culture of Spontaneity: Improvisation and the Arts in Postwar America, University of Chicago Press, Chicago.

Bilton, C. and Cummings, S. (2014), Handbook of management and creativity, Edward Elgar Publishing, Cheltenham, UK.

Bingham, C.B. and Eisenhardt, K.M. (2011), "Rational heuristics: the 'simple rules' that strategists learn from process experience", Strategic Management Journal, Vol. 32, pp. 1437-1464.

Brown, S.L. and Eisenhardt, K.M. (1997), "The art of continuous change: linking complexity theory and time-paced evolution in relentlessly shifting organizations", Administrative Science Quarterly, Vol. 42, pp. 1-34.

Candy, L. and Edmonds, E. (2011). Interacting: art, research and the creative practitioner, Libri Publishing, Faringdon.

Carter, C. (2000), "Improvisation in dance", Journal of Aesthetics and Art Criticism, Vol. 58, No. 2, pp. 181-190.

Chetty, S.K. (1996), "The case study method for research in small and medium sized firms", International Small Business Journal, Vol 15, No. 1, pp. 73-85.

Cochrane, P, Craft, A. and Jeffery, G. (2008), "Mixed messages or permissions and opportunities? Reflections on current policy perspectives on creativity in education", in J. Sefton-Green (ed.), Creative Learning, London: Arts Council of England.

Crossan, M.M., Lane, H., White, R.E. and Klus, L. (1996), "The improvising organization: where planning meets opportunity”, Organizational Dynamics, Vol. 24, pp. 20-35.

Csikszentmihalyi, M. (1988), "Society, culture and person: a systems view of creativity”, in R.J. Sternberg (ed.), The nature of creativity (pp. 325-339), Cambridge, University Press, Cambridge.

Cummings, S., Bilton, C. and ogilvie, d. (2014), "Towards a new understanding of creativity dynamics: from one-size-fits-all models to multiple and dynamic forms of creativity", Technology Innovation Management Review, Vol. 5, No. 7, pp. 14-24. Cunha, da J.V. and Cunha, e M.P. (2010), "Organizational improvisation: change or stability?”, Management Research, Vol. 8, No. 2, pp. 81-100. Cunha, M.P., Cunha, J.V. and Kamoche, K. (1999), "Organizational improvisation: what, when, how and why", International Journal of Management Reviews, Vol. 1, 
pp. 299-341.

Curran, J. and Blackburn, A. (2001), Researching the small enterprise, Sage, London. Darso, L. (2004), Artful creation - learning tales of arts in business, Narayana Press, Gylling, Denmark.

Denzin, N.K. and Lincoln, Y.S. (2003), The landscape of qualitative research: theories and issues, $2^{\text {nd }} \mathrm{ed}$, London: Sage.

Dewalt, K.M. and Dewalt, B.R. (1998), Participant observation, in Bernard, H.R. Handbook of methods in cultural anthropology, Altamira Press, CA.

Esslin, M. (1987), The Field of Drama, Verso, London.

Fiske, E. (1999), Champions of change: the impacts of the arts on learning, Arts Education Partnership and President's Committee on the Arts and the Humanities, Washington DC.

Foucault, M. (1972), The Archaeology of knowledge, and the discourse of language, trans, A.M. Sheridan Smith, Pantheon Books, New York, NY.

Frost, A. and Yarrow, R. (1990), Improvisation in Drama. Macmillan, Basingstoke. Gagnon, S., Vough, H.C. and Nickerson, R. (2012), "Learning to lead, unscripted: developing affiliative leadership through improvisational theatre", Human Resource Development Review, Vol. 11, pp. 299-325.

Geertz, C. (1973), Thick description: toward an interpretive theory of culture, in The interpretation of cultures: selected essays (pp. 3-30), Basic Books, New York.

Giddens, A. (1986), The constitution of society: an outline of the theory of structuration, University of California Press, Berkeley, CA.

Gifford, S. (1998), "Analysis of non-numerical research", in Kerr, C., Taylor, R. and Heard, G. (Eds), Handbook of Public Health Methods, McGraw-Hill, Maidenhead. Glaser, B. and Strauss, A. (1967), The Discovery of Grounded Theory: Strategies for Qualitative Research, Wiederfield and Nicholson, London.

Goffman, E. (1959), The presentation of self in everyday life, Doubleday, Garden City, NY.

Govan, E., Nicholson, H., Normington, K. (2009), Making a Performance: Devising Histories and Contemporary Practices, Routledge. London and New York.

Hadida, A.L., Tarvainan, W. and Rose, J. (2015), "Organizational improvisation: a consolidating review and framework", International Journal of Management Reviews, Vol. 17, pp. 437-459.

Heddon, D. and Milling, J. (2006), Devising Performance: A Critical History, Palgrave Macmillan, Basingstoke.

Herridge, F. (1969), "The avant-garde is at it again", review of dance performance by Yvonne Rainer, New York Post, $7^{\text {th }}$ Feb., reprinted in Rainer, Word 1961-73, p. 155. Jamebekar, A.B. and Pelc, K.I. (2007), "Improvisation model for team performance enhancement in a manufacturing environment", Team Performance Management, Vol. 13, No. 7/8, pp. 259-274.

Johnson, J.M. (1975), Doing field research, Free Press, New York.

Johnston, C. (2006), The Improvisation Game: Discovering the Secrets of

Spontaneous Performance, Nick Hern Books, London.

Jorgensen, D.L. (1989), Participant observation: a methodology for human studies, Sage, London.

Kao, J. (1996), Jamming: The art and discipline of business creativity, HarperCollins, New York, NY.

Kershaw, B (1999), The Radical in Performance: Between Brecht and Baudrillard, Routledge, London and New York.

Kershaw, B. (2007), "Performance, community, culture, in Kuppers, P., Robertson, G. 
(eds.), The Community Performance Reader (pp.77-96), Routledge, London and New York.

Kuppers, P., Robertson, G. (eds.) (2007), The Community Performance Reader, Routledge, London and New York.

Mantere, S., Sillince, J.A.A. and Hamalainen, V. (2007), "Music as a metaphor for organizational change", Journal of Organizational Change Management, Vol. 20, pp. 447-459.

Maxwell, J. (1990), Qualitative research design, Sage, CA.

McCarthy, K.F., Ondaatje, E.H., Zakaras, L. and Brookes, A. (2004), Gifts of the muse - reframing the debate about the benefits of the arts, Rand Corporation. McCracken, G. (1988), The long interview, in Arksey, H. and Knight, P. (1999), Interviewing for social scientists, Sage, London.

Orlikowski, W.J. and Hofman, J.D. (1997), “An improvisational model for change management: the case of groupware technologies", Sloan Management Review, Winter, Vol. 38, No. 2, pp. 11-21.

Perren, L. and Ram, M. (2004), Case study method in small business and entrepreneurial research: mapping boundaries and perspectives, International Small Business Journal, Vol. 22, No. 1, pp. 83-101.

Plowman, D.A., Baker, L.T., Beck, T.E., Kulkarni, M., Solansky, S.T. and Travis, D.V. (2007), "Radical change accidentally: the emergence and amplification of small change", Academy of Management Journal, Vol. 50, pp 515-543.

Prichard, C. (2002), 'Creative selves? Critically reading 'creativity' in management discourse”, Creativity and Innovation Management, Vol. 11, No. 4, pp. 265-276. Ratten, V. and Hodge, J. (2016), "So much theory, so little practice: a literature review of workplace improvisation training", Industrial and Commercial Training, Vol. 48, No. 3, pp. 149-155.

Rickards, T. \& Moger, S. (1999), Handbook for creative team leaders, Gower Publishing Limited, Aldershot, UK.

Schiuma, G. (2011), The Value of Arts for Business, Cambridge University Press, Cambridge.

Schiuma, G. (2014), "New measures of creativity", available online at http://www.aqr.org.uk/a/20141130-new-measures, accessed $8^{\text {th }}$ Dec., 2015. Shaughnessy, N. (2012), Applying Performance: Live Art, Socially Engaged Theatre and Affective Practice, Palgrave Macmillan, London.

Sinfield, J.; Gustafson, T. and Hindo B. (2014), "The Discipline of Creativity", MIT Sloan Management Review, Winter, Vol. 55, No. 2.

Staricoff, R.L. (2004), Arts in Health: A review of the medical literature, Arts Council England, London.

Steinman, L. (1995). The Knowing Body: The Artist as Storyteller in Contemporary Performance, North Atlantic Books, Berkeley.

Sternberg R.J. (1988), The nature of creativity, Cambridge University Press, Cambridge.

Sterritt, D. (2000), "Revision, prevision and the aura of improvisatory art", Journal of Aesthetics and Art Criticism, Vol. 58, No. 2, pp. 163-172.

Sudnow, D. (1978), Ways of the hand, Harvard University Press, MA. Weick, K.E. (1987), "Substitutes for strategy", in D.J. Teece (ed.), The competitive challenge: strategies for industrial innovation and renewal (pp. 222-233), Ballinger, Cambridge, MA. Yin, R.K. (2003), Case study research-design and method, $3^{\text {rd }}$ ed, Sage: CA. 
Table 1 Summary of data collection

\begin{tabular}{|l|l|}
\hline Description (number of participants) & Data \\
\hline $\begin{array}{l}\text { Observations of day-to-day running of } \\
\text { the factory, interactions between staff, } \\
\text { corporate historical and promotional } \\
\text { materials }\end{array}$ & $\begin{array}{l}\text { Participant observer field notes } \\
\text { (performance devising stage), audio- } \\
\text { visual recordings, collected materials }\end{array}$ \\
\hline $\begin{array}{l}\text { Preliminary interviews with staff about } \\
\text { their roles within the firm, factory floor } \\
\text { tours, informal discussions }\end{array}$ & $\begin{array}{l}\text { Participant observer field notes } \\
\text { (performance devising stage), interview } \\
\text { data, transcripts, audio-visual recordings }\end{array}$ \\
\hline $\begin{array}{l}\text { Artistic critical reflection of performance } \\
\text { development (choreographer/composer) }\end{array}$ & Interview transcripts \\
\hline $\begin{array}{l}\text { Snapshot interviews with firm managers } \\
\text { (2) and colleagues (6) }\end{array}$ & $\begin{array}{l}\text { Audio-visual recordings, interview } \\
\text { transcripts, video edits 00:44:36 }\end{array}$ \\
\hline $\begin{array}{l}\text { Snapshot interviews with Assault } \\
\text { performers (3) and staff, including one } \\
\text { researcher (2) }\end{array}$ & $\begin{array}{l}\text { Audio-visual recordings, interview } \\
\text { transcripts, video edits 01:31:22 } \\
\text { hrs:mins:secs }\end{array}$ \\
\hline Recorded Performance (P) & $\begin{array}{l}\text { Audio-visual recordings, interview } \\
\text { transcripts, video edits 00:37:22 } \\
\text { hrs:mins:secs }\end{array}$ \\
\hline $\begin{array}{l}\text { Interviews with firm staff 10 months post } \\
\text { event }\end{array}$ & $\begin{array}{l}\text { Audio-visual recordings, interview } \\
\text { transcripts, audio edits 01:02:00 } \\
\text { hrs:mins:secs }\end{array}$ \\
\hline
\end{tabular}

Table 2 The devised performance: sections

\begin{tabular}{|l|l|l|}
\hline Section & $\begin{array}{l}\text { Summary of } \\
\text { Section }\end{array}$ & Description \\
\hline Chitting & Opening & $\begin{array}{l}\text { Used large packing boxes used by the business to } \\
\text { mimic pollinating tents used in the greenhouses. } \\
\text { Boxes were placed on their side and dancers } \\
\text { performed within the boxes, backlit by industrial } \\
\text { lights provided by the business. } \\
\text { Movement material was devised through exploring } \\
\text { ideas of chitting and germination. } \\
\text { Soundtrack was created through layering electronic } \\
\text { sounds with recordings made on-site of bees and } \\
\text { flies in the pollinating tents. }\end{array}$ \\
\hline Ropes & $\begin{array}{l}\text { Movement material reflected the description of the } \\
\text { task, and was devised by exploring movements } \\
\text { early industry } \\
\text { / making } \\
\text { Ropes }\end{array}$ & $\begin{array}{l}\text { Soundtrack was constructed using samples made } \\
\text { from manipulated recordings of machinery used on- } \\
\text { site, combined with spoken word, using text from a } \\
\text { booklet charting Elsoms' history, read by a staff } \\
\text { member. } \\
\text { Text excerpt: Rope making by hand worked on the } \\
\text { same principle as spinning a simple woolen thread, } \\
\text { though on a much coarser scale. The men worked in } \\
\text { pairs. One man walked backwards, paying out the } \\
\text { fibres between his finger and thumb from a bundle } \\
\text { held in his arms, whilst the other remained at the }\end{array}$ \\
\hline &
\end{tabular}


starting point and twisted the growing cord by means of a revolving hook mounted on a post. Every few yards along the pathway were hurdles, or other wooden supports, at about waist height, to take the weight of the cord and hold it clear of the ground. Later, a number of these cords, lying side by side on the supports, could be twisted into a thicker rope by a roughly similar process, one man remaining at the twisting hook, the other walking backwards with a wooden block through which the cords had been threaded (p3).

\begin{tabular}{|c|c|c|}
\hline Obituary & $\begin{array}{l}\text { Passing on of } \\
\text { company and } \\
\text { responsibility } \\
\text { from father to } \\
\text { son }\end{array}$ & $\begin{array}{l}\text { Focussed on the company's history, created through } \\
\text { a choreographic task of handing on, refusing and } \\
\text { accepting. } \\
\text { Soundtrack included a live violin part performed by } \\
\text { a staff member related to the company story on a } \\
\text { number of levels: a maintenance worker at Elsoms } \\
\text { during the 1940s had made violins in his spare time; } \\
\text { the staff member was a violinist but had not played } \\
\text { for } 20 \text { years prior to taking part in this project; she } \\
\text { played on a violin made for her by her grandfather. } \\
\text { Instrumental aspects of the soundtrack were overlaid } \\
\text { with spoken word, using the } 1901 \text { obituary of } \\
\text { George Elsom, read by a staff member. } \\
\text { Excerpt from obituary: The Circuit generally, and } \\
\text { the Crescent Church in particular, has been } \\
\text { profoundly grieved during the past month by the } \\
\text { death of our dear friend, Mr. George Elsom. For } \\
\text { more than a year past, Mr Elsom had heroically and } \\
\text { patiently born affliction and sorrow such as would } \\
\text { have crushed a less saintly spirit. In spite of all that } \\
\text { we was called upon to endure, her never murmured } \\
\text { or repined, his faith never wavered, and to the last } \\
\text { he exhibited a beautiful submission to God's will } \\
\text { that was a real inspiration to all who were brought } \\
\text { into contact with him ... We scarcely dare to think } \\
\text { what his loss means to his loved ones (p7). }\end{array}$ \\
\hline $\begin{array}{l}\text { Elsoms } \\
\text { Competition } \\
1934\end{array}$ & Humor & $\begin{array}{l}\text { Depicting a newspaper competition held in } 1934 \text { to } \\
\text { name the new company offices. } \\
\text { Movement was generated through physically } \\
\text { representing each line of competition text, } \\
\text { performed in time to a recorded reading of the } \\
\text { advert. }\end{array}$ \\
\hline Processes & Work & $\begin{array}{l}\text { Explored the physical work undertaken at the } \\
\text { business on the factory floor, incorporated physical } \\
\text { objects used (eg., seed dye containers) and } \\
\text { protective clothing (including overalls dyed with } \\
\text { seed dye, face masks and high visibility jackets). } \\
\text { Objects and clothing were provided by the company } \\
\text { and overalls were dyed by employees. }\end{array}$ \\
\hline
\end{tabular}


Soundtrack reflected current work of the company, incorporating spoken word and including 13 stages of parsnip seed production identified by an employee. Incorporated information from the company promotional material describing firm services. Reprise of the passing on of the company and responsibility from father to son over the company's history again, including a live violin part performed by a staff member. Focused on one particular historical member of staff, Minnie Hardy, a pioneer of seed science who worked for the company in the 1920s. Minnie worked in the back bedroom of Elsoms family home, germinating seeds in germinating tanks and gas-heated incubators. Excerpt from booklet charting Elsoms' history: In one of the incubators, Brassica seed samples in Petrie dishes were tested; clovers stacked between folds of blotting paper went into the other. Both incubators had gas-heated hot water jackets to maintain the correct temperature. Beside them stood an open galvanized tank of hot water, again gasheated, with strips of glass resting across it. On each of these were discs of filter paper, kept moist by filter paper wick that dipped down into the water between the strips of glass. To test a sample of grass seed, Minnie would count out one hundred seeds onto each of five filter papers; later, she counted how many had germinated, and took the average of the five tests as the percentage germination rate. Movement material was generated by exploring the folding and stacking described in the above text, and the monotony of repetitive tasks.

Soundtrack was a song, performed live by one of the performers.

Accompaniment to vocal included live violin, performed by a staff member as well as samples made from manipulated recordings of machinery on-site, a recording of a washing machine cycle (drawing out ideas of working within domestic environments) and spoken word, reciting from 1100 (to reflect Minnie counting of seeds).

Referenced the cumulative nature of the firm's product output, cumulatively structuring a piece of movement material.

Soundtrack used a cumulative structure, layering electronic sounds with spoken word referencing products and categories from a product catalogue. Focused on the current business. 


\begin{tabular}{|l|l|}
\hline & Movement material was generated by exploring \\
& movement related to scattering and manipulating \\
& seed. \\
& Solo dancer performed in a rope circle, scattering a \\
box of seed provided by the company. The dancer \\
also scattered slips of paper, each written with the \\
name of a current member of staff. \\
Soundtrack referenced the opening of the show with \\
a repetition of the electronic sounds used but also \\
included spoken word overlaying the electronic \\
sounds. \\
Staff had responded to the question 'What do you \\
like best about working at Elsoms?' For anonymity \\
their answers were spoken and recorded by \\
performers.
\end{tabular}

